\title{
Good News on New Goods for MRS Bulletin
}

The masthead page of MRS Bulletin does not make for riveting reading. The names of the Bulletin staff and the Editorial Board show up regularly each month, but how they play into each published issue is probably not clear to our readers. I want to take the time this month to describe a number of new features in the Bulletin that are beginning with this issue, each of which is due to the resourcefulness and hard work of the people listed on that page.

The most prominent feature of the Bulletin is the monthly theme, which provides a multi-article overview of an important area of materials research. According to MRS member surveys and the ISI Citation Index data, these review articles are highly valued by our readers, so we are undertaking two initiatives to further enhance their value.

First, we are aware that many of our readers rely on the theme articles within the Bulletin to serve as an entry into an unfamiliar field. To ensure that we are providing the best possible introduction for non-specialists, we will be reinforcing the tutorial nature of the introductory article for each theme. This short tutorial will be provided by our Guest Editors, who are chosen based on their expertise and perspective in their respective fields.

Second, beginning with this issue, we are expanding the scope of the topics that the Bulletin offers by regularly publishing a

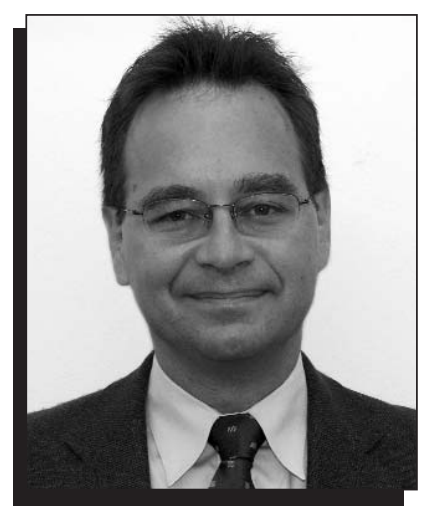

Paul Drzaic

single article overview of a second, standalone topic. This format will enable the Bulletin to cover emerging research topics as well as highly specialized niches of research that would not support a multiarticle theme. Think of it as a way of doubling the breadth of the Bulletin's coverage of important research areas.

While the themes are the most prominent aspect of the Bulletin, the magazine also plays a role in reporting on news and activities central to MRS members and the materials community. To that end, we are introducing a new feature this month, INTERFACES, which is focused on the people in materials research and how they make an impact through their work. This feature will cover a broad spectrum of topics, from education to business to public outreach. Launching the feature is an interview with Eugene Fitzgerald of the Massachusetts Institute of Technology and co-founder of AmberWave Systems Corp., who will let us in on how he transformed his materials innovation into a successful startup company.

We have several additional initiatives underway, including enhanced coverage of materials conferences; the use of the Web to complement the offerings in the printed Bulletin; and a special, extended Bulletin issue on a topic of major importance. Again, these initiatives are only possible due to the hard work of the Bulletin staff, the Editorial Board, the Volume Organizers, and Visiting Scientists, who really make these features happen.

As always, we will ultimately be judged by our readership: we want to educate our readers, serve as a leading citation source in materials research, and provide information of importance to MRS members. We'd love to hear how you think we're doing: please send any comments you have to Bulletin@mrs.org.

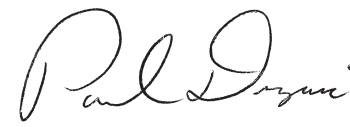

Paul DRZAic Chair, MRS Bulletin Editorial Board 